\title{
MATERNAL HYPERTENSION AS A RISK FACTOR ASSOCIATED WITH LOW BIRTH WEIGHT
}

\author{
Simone Seixas da Cruz*/**, Isaac Suzart Gomes-Filho**, Johelle de Santana Passos-Soares**/****, \\ Luise Maria Souza*, Ana Claudia Morais Godoy Figueiredo*, Priscila Santos Pinto***, \\ Rosane Silvia Davoglio***, Soraya Castro Trindade** \\ Corresponding author: Simone Seixas da Cruz - simone.seixası@gmail.com \\ * Department of Epidemiology, Federal University of Recôncavo da Bahia (UFRB), Santo Antônio de Jesus, Bahia, Brazil \\ ** Department of Health, Feira de Santana State University, Feira de Santana, Bahia, Brazil \\ *** Department of Epidemiology, Federal University of Vale do São Francisco (UNIVASF), Petrolina, Pernambuco, Brazil \\ **** Department of Preventive Dentistry, Federal University of Bahia, Salvador, Bahia, Brazil
}

\begin{abstract}
Objective: to investigate the association between maternal hypertension and low birth weight, in a public hospital in Petrolina, Pernambuco, Brazil. Methods: A case-control study was conducted on 317 individuals, such that the case group was composed of 87 mothers of children born with a weight of less than $2500 \mathrm{~g}$ and/or gestational age less than 37 weeks, and the control group was composed of 230 mothers of newborns of weight greater than or equal to $2500 \mathrm{~g}$ and gestational age greater than or equal to 37 weeks. Descriptive analysis and logistic regression were applied to the data gathered. Results: The results showed a statistically significant difference in maternal age between the study groups. The use of medications and number of prenatal consultations were also shown to be associated with low birth weight. After appropriate adjustments, the association between maternal hypertension and low birth weight was demonstrated to be strong and statistically significant $(\mathrm{OR}=3.84 ; 95 \% \mathrm{Cl}: 1.92-7.68)$. Conclusions: The findings indicate that maternal hypertension is a possible risk factor for low birth weight.
\end{abstract}

Keywords: Hypertension; Low-weight newborn; Child mortality; Odds ratio; Risk factors.

\section{INTRODUCTION}

Low birth weight (LBW) is considered to be one of the most important public health problems. It is one of the general health indicators for the population and predicts quality of life, health system efficiency ${ }^{(1)}$ and, especially, child morbidity and mortality. ${ }^{(2)}$ The World Health 
Organization (WHO) defines LBW as all cases in which the child weighs less than $2.5 \mathrm{~kg}$ at birth. (3) LBW is a consequence of a shorter gestational period, intrauterine growth restriction or an association between these two factors, as well as a variety of correlated maternal factors, such as arterial hypertension or other associated disease during the pregnancy, infections during the pregnancy, socioeconomic factors, lifestyle habits and reproductive history, among others. ${ }^{(4)}$

According to recent international estimates dating from between 2000 and 2007 , the mean rate of LBW among newborns is around $14 \%$. This figure may vary from $4 \%$ in Finland up to $28 \%$ in countries like India. Consolidated data from the United Nations Children's Fund (UNICEF) reveal that the prevalence of LBW in the industrialized countries was around $7 \%$, over the years 2000 to 2007 . On the other hand, in developing countries, this figure reached around $15 \% .{ }^{(5)}$

In Brazil, this rate was of the order of $7.6 \%$ in the year 2000 and $8.2 \%$ in 2007 , but it is known that there are notable variables between different regions of the country. For example, the rate was $9.1 \%$ in the southeastern region and $7.5 \%$ in the northeastern region, in the year 2007. The Brazilian Ministry of Health has attributed these contrasting data to the greater reliability of the data from the southern and southeastern regions. In Pernambuco, this incidence ranged from $7.0 \%$ in 2000 to $7.6 \%$ in $2007{ }^{(6)}$

LBW constitutes one of the main single causes of neonatal, perinatal and infant mortality. Studies have demonstrated that LBW is strongly associated with the risk that children may become ill and die during their first year of life. Even though low weight newborns only comprise 7 to $10 \%$ of all live births, they account for two thirds of all neonatal deaths. ${ }^{(7)}$ LBW and prematurity are determining factors in neonatal infections and higher rates of hospitalization, and they are significantly related to greater propensity towards delayed growth, postnatal neurological deficits and low school performance. ${ }^{(8)}$
Among the factors that contribute towards LBW, arterial hypertension can be highlighted as one of the most important of them. According to the Brazilian Ministry of Health, hypertensive complications during pregnancy are the greatest cause of maternal and fetal morbidity and mortality, and such complications occur in around 10\% of all pregnancies. ${ }^{(9)}$ The etiology of hypertensive disorders is still unknown, but they constitute the greatest cause of maternal death in Brazil and the second greatest cause in the United States. ${ }^{(10,11)}$ A study carried out in São Paulo indicated that hypertensive disorders were the leading cause of maternal and fetal mortality, representing $23.3 \%$ of the maternal deaths investigated. ${ }^{(11)}$

Hypertension during pregnancy has been given the general name of Gestational Hypertensive Syndrome (GHS). ${ }^{(12)}$ Independent of type, hypertension is defined as systolic blood pressure greater than or equal to $140 \mathrm{mmHg}$ and diastolic blood pressure greater than or equal to $90 \mathrm{mmHg}$. GHS is classified as chronic arterial hypertension, preeclampsia/ eclampsia, chronic hypertension with associated preeclampsia and gestational hypertension. ${ }^{(9,10)}$

Gestational hypertensive disorders have been indicated as some of the main factors contributing towards higher rates of preterm delivery, stillborn fetuses and neonatal morbidity. Maternal hypertensive syndromes give rise to high rates of cesarean deliveries, because of the compromised maternal and fetal condition. Furthermore, it has been demonstrated that abnormalities caused by hypertension during pregnancy may reduce the uterine-placental flow, thus giving rise to fetal hypoxia, low weight, preterm delivery and newborns that are small for the gestational age. ${ }^{(10,12)}$

These points therefore justified the present study, which had the aim of evaluating occurrences of this disorder and its association with LBW in a public hospital in Petrolina, State of Pernambuco, Brazil, given that studies on this population are scarce and there is an urgent need for data that would provide backing for defining appropriate policies and strategies for maternal and neonatal health. 


\section{MATERIALS AND METHODS}

\section{STUDY DESIGN AND SAMPLE}

This case-control study was conducted among puerperae attended at Hospital Dom Malan, in Petrolina, Pernambuco, Brazil, independent of the municipality in which these women lived, between June and October 2009. Hospital Dom Malan is a general hospital administered by the municipality that only attends patients through the Brazilian National Health System (SUS). It is regarded as a high-complexity reference hospital for the entire São Francisco valley region, and is the only public institution in the region that has a neonatal Intensive Care Unit (ICU).

To form the case and control groups, the cases were defined as mothers whose children were born with a weight of less than $2500 \mathrm{~g}$ or a gestational age of less than 37 weeks, while the controls were defined as mothers whose children were born with a weight of greater than or equal to $2500 \mathrm{~g}$ or a gestational age of more than 37 weeks.

The sample size for this study was calculated using the Epi Info software (version 6.0), taking the following parameters that are available in the literature:(10) frequency of maternal hypertension of $64.7 \%$ among mothers in the case group and $23.4 \%$ among mothers in the control group. The minimum sample size was estimated as 93 cases and 186 controls, thus making a total of 279 participants, taking a confidence level $(\alpha)$ of $95 \%$ and a study power $(\beta)$ of $80 \%$. It was decided to double the number of controls, since it was foreseen that there might be some difficulty in identifying women in the case group, given that the outcome is considered to be a rare event.

\section{SAMPLE SELECTION}

Individuals were selected for the sample through firstly choosing puerperae who were eligible to participate in the case and control groups, according to data gathered from the hospital's daily register of births relating to the weight and gestational age of the newborns. This was done every week for four months.

All mothers of low-weight newborns who were still in the institution following the delivery at the time of the selection, along with those who returned to the hospital with their children not more than one week after the delivery, were invited to form part of the case group. The control group was also recruited through the same source, over the same period as for the case group, and was selected by using a random numbers table. Puerperae who presented cardiovascular diseases or any other systemic abnormality, and those who required antibiotic prophylaxis for dental procedures to be performed or who had previously undergone periodontal treatment during pregnancy, were excluded.

\section{DATA GATHERING PROCEDURES}

All the participants were properly informed about the study and they all signed a free and informed consent statement. This project had firstly been submitted to and approved by the Research Ethics Committee of Feira de Santana State University, Feira de Santana, Bahia (CAAE 0151.0.059.000-08) and has been followed the Helsink's recommendations for conduct clinical research in human subjects.

After giving consent, the participants were interviewed at an arranged time, through a questionnaire that asked for the following types of information: identification, sociodemographic data, gestational history, lifestyle habits and oral health characteristics.

Another source of information that was used was the pregnant woman's card, which served as backing for gathering information about prenatal care, such as blood pressure measurements, gestational age, number of consultations and use of medications, among other factors.

The parameters used to determine cases of maternal hypertension were blood pressure measurements greater than $140 \times 90 \mathrm{mmHg}$ recorded on the pregnant woman's card at one or more prenatal consultations, and declarations 
by the interviewee that arterial hypertension had occurred during the pregnancy, with investigations in the hospital medical files.

At the time of the interview, the puerpera's blood pressure was measured using an appropriate technique and reliable and duly calibrated equipment, while respecting the recommendations for this procedure. ${ }^{(13)}$ The purpose of this measurement was to make an attempt to evaluate the quality of the blood pressure information recorded on the pregnant woman's card.

Following this, a single dental surgeon carried out a periodontal clinical examination in the mobile dental consultation office. This was directed towards identifying the existence of any periodontal disease among the participants, in accordance with the criteria proposed in the literature. ${ }^{(14)}$

\section{DATA ANALYSIS}

After the data gathering had been completed, descriptive analysis on the main dependent variable (LBW) and all the covariables considered in the study was conducted by means of numerical measurements. Simple frequencies were obtained, and statistical differences were assessed using the Pearson chi-square test, with a significance level of $5 \%$.
To evaluate the association between maternal hypertension and LBW, Odds Ratios (OR) were estimated as a measurement of such associations, along with the respective $95 \%$ confidence intervals. Through unconditional logistic regression analysis, the presence of effect-modifying covariables was investigated using the maximum likelihood ratio test $(p<0.05)$, and the roles of confounding variables were assessed by means of the backward strategy. The STATA software, version 9.0, was used for processing and analyzing the data.

\section{RESULTS}

In total, 317 mothers were involved in the study, of whom 230 were in the control group and 87 were in the case group. Analysis on occurrences of LBW according to the maternal sociodemographic characteristics (table 1) showed that there was a statistically significant difference with regard to maternal age $(p=0.01)$. Among the mothers less than 19 years of age and over 35 years of age, the proportion of LBW (32.2\%) was relatively greater than among the mothers who had children with normal weight $(18.7 \%)$, thus obtaining an OR of 2.06 (95\% Cl: 1.12- 3.73). However, when other characteristics were evaluated, no statistically significant differences between the case and control groups were identified for any of them.

Table 1 - Sociodemographic characteristics of the cases and controls, with respective odds ratios and confidence intervals. Petrolina, $2010(n=317)$

(continued)

\begin{tabular}{|c|c|c|c|c|c|c|}
\hline \multirow{2}{*}{ VARIABLES } & \multicolumn{2}{|c|}{ CASES $(N=87)$} & \multicolumn{2}{|c|}{ CONTROLS $(\mathrm{N}=230)$} & \multirow{2}{*}{ OR } & \multirow{2}{*}{$95 \% \mathrm{Cl}$} \\
\hline & $\mathbf{N}$ & $\%$ & $\mathbf{N}$ & $\%$ & & \\
\hline \multicolumn{7}{|l|}{ Maternal age } \\
\hline .19 and .35 years & 28 & 32.2 & 43 & 18.7 & 2.06 & $(1.12-3.73)$ \\
\hline$>19$ and < 35 years & 59 & 67.8 & 187 & 81.3 & & \\
\hline \multicolumn{7}{|l|}{ Maternal schooling } \\
\hline O - 4 years & 11 & 12.6 & 28 & 12.2 & 1.04 & $(0.45-2.29)$ \\
\hline+4 years & 76 & 87.4 & $2 \mathrm{O} 2$ & 87.4 & & \\
\hline \multicolumn{7}{|l|}{ Family income } \\
\hline .1 minimum salary & 60 & 69.0 & 150 & 65.2 & 1.18 & $(0.68-2.10)$ \\
\hline$>1$ minimum salary & 27 & 31.0 & 80 & 34.8 & & \\
\hline
\end{tabular}


Table 1 - Sociodemographic characteristics of the cases and controls, with respective odds ratios and confidence intervals. Petrolina, $2010(\mathrm{n}=317)$

\begin{tabular}{|c|c|c|c|c|c|c|}
\hline \multirow{2}{*}{ VARIABLES } & \multicolumn{2}{|c|}{ CASES $(N=87)$} & \multicolumn{2}{|c|}{ CONTROLS $(N=230)$} & \multirow{2}{*}{ OR } & \multirow{2}{*}{$95 \% \mathrm{Cl}$} \\
\hline & $\mathrm{N}$ & $\%$ & $\mathrm{~N}$ & $\%$ & & \\
\hline \multicolumn{7}{|l|}{ Conjugal situation } \\
\hline Single or widowed & 16 & 16.4 & 39 & 17.0 & 1.1 & $(0.54-2.17)$ \\
\hline Married or stable partnership & 71 & 81.6 & 191 & 83.0 & & \\
\hline \multicolumn{7}{|c|}{ Mother's occupation before pregnancy } \\
\hline Unpaid activities & 36 & 41.4 & 77 & 33.6 & 1.39 & $(0.81-2.38)$ \\
\hline Paid activities & 51 & 58.6 & 152 & 66.4 & & \\
\hline \multicolumn{7}{|c|}{ Mother's occupation during pregnancy } \\
\hline Unpaid activities & 58 & 66.7 & 149 & 65.1 & 1.07 & $(0.62-1.89)$ \\
\hline Paid activities & 29 & 33.3 & 80 & 34.9 & & \\
\hline
\end{tabular}

It was also found that there was an association between LBW and the use of medications during pregnancy $(\mathrm{OR}=2.16 ; 95 \% \mathrm{Cl}: 1.11-4.42)$. The number of prenatal consultations was also an important factor when compared between the two groups. Among the mothers who went to fewer than three consultations during their pregnancies, 33.4\% were in the case group, whereas $13.04 \%$ were in the control group (OR: $3.33 ; 95 \% \mathrm{Cl}$ : 1.77-6.24) (table 2)

Table 2 - Lifestyle and medical-dental characteristics of the cases and controls, with respective odds ratios and confidence intervals. Petrolina, $2010(n=317)$

\begin{tabular}{|c|c|c|c|c|c|c|}
\hline \multirow{2}{*}{ VARIABLES } & \multicolumn{2}{|c|}{ CASES $(N=87)$} & \multicolumn{2}{|c|}{ CONTROLS $(N=230)$} & \multirow{2}{*}{ OR } & \multirow{2}{*}{$95 \% \mathrm{Cl}$} \\
\hline & $N$ & $\%$ & $N$ & $\%$ & & \\
\hline \multicolumn{7}{|l|}{ Urinary infection $^{a}$} \\
\hline Yes & 39 & 45.3 & 92 & 40.0 & 1.24 & $(0.73-2.11)$ \\
\hline No & 47 & 54.7 & 138 & 60.0 & & \\
\hline \multicolumn{7}{|l|}{ Diabetes } \\
\hline Yes & 4 & 4.6 & 2 & 0.9 & 5.49 & $(0.77-61.39)$ \\
\hline No & 83 & 95.4 & 228 & 99.1 & & \\
\hline \multicolumn{7}{|l|}{ Use of medications $^{a}$} \\
\hline Yes & 73 & 83.9 & 162 & 70.7 & 2.16 & $(1.11-4.42)$ \\
\hline $\begin{array}{l}\text { No } \\
\text { Number of prenatal }\end{array}$ & 14 & 16.1 & 67 & 29.3 & & \\
\hline $\begin{array}{c}\text { consultations } \\
\text { O to } 3\end{array}$ & 29 & 33.3 & 30 & 13.0 & 3.33 & $(1.77-6.24)$ \\
\hline 3 or more & 58 & 66.7 & 200 & 87.0 & & \\
\hline \multicolumn{7}{|c|}{ Alcohol consumed during pregnancy } \\
\hline Yes & 12 & 13.8 & 15 & 6.5 & 2.29 & $(0.93-5.49)$ \\
\hline No & 75 & 86.2 & 215 & 93.5 & & \\
\hline \multicolumn{7}{|c|}{ Periodontal disease present ${ }^{b}$} \\
\hline Yes & 21 & 24.1 & 56 & 24.8 & 0.97 & $(0.51-1.77)$ \\
\hline No & 66 & 75.9 & 170 & 75.2 & & \\
\hline
\end{tabular}

${ }^{\mathrm{a}}$ One observation was lost.

${ }^{\mathrm{b}}$ Four observations were lost. 
Analysis on the crude association between maternal hypertension and LBW showed that the hypertensive mothers had a chance of having low- weight children that was around four times greater than among the mothers without this condition $(\mathrm{OR}=4.27 ; 95 \% \mathrm{Cl}: 2.18-8.35)$ (table 3 ).

Table 3 - Odds ratios and confidence intervals obtained through logistic regression for the association between maternal hypertension and low birth weight. Petrolina, Pernambuco, Brazil, $2010(N=317)$

\begin{tabular}{cccc}
\hline MODELS & $\mathrm{N}$ & OR & $95 \% \mathrm{Cl}$ \\
\hline Crude & 317 & 4.27 & $2.18-8.35$ \\
Adjusted $^{a}$ & 317 & 3.84 & $1.92-7.68$ \\
\hline
\end{tabular}

${ }^{a}$ Adjusted for maternal age, urinary infection, number of prenatal consultations and use of medications.

In stratified analysis, only the use of medications was identified as a potential confounder. However, using theoretical confounding criteria recorded in the literature, the variables of maternal age, urinary infection during pregnancy, number of prenatal consultations and use of medications during pregnancy were used as confounders in the unconditional multivariate logistic regression analysis. After appropriate adjustments had been made for these covariables, the association measurement decreased but remained strong and statistically significant $(\mathrm{OR}=3.84 ; 95 \% \mathrm{Cl}: 1.92-7.68)$.

\section{DISCUSSION}

According to the findings obtained from this case-control study design, which was strategically appropriate for the rareness of the outcome (LBW), ${ }^{(15)}$ a strong association was found between maternal hypertension and LBW, with statistical significance. Other studies with methodological variations reinforce these findings, ${ }^{(10,16-18)}$ although the magnitude of this association was found to be greater in the present study.

Given the multicausal nature of LBW and the vulnerability of the association hypothesis to the action of confounders, ${ }^{(19,20)}$ an effort was made to deal with variables that are classically considered to be confounders (maternal age, urinary infection during pregnancy, number of prenatal consultations and use of medications), which would be capable of dis- torting the epidemiological measurement obtained. However, even after appropriate adjustment procedures, the association was maintained in magnitude and precision.

Despite the methodological presuppositions made for the present study, we still acknowledge that are some limitations in relation to the criteria adopted for defining the exposure measurement (arterial hypertension). This measurement was obtained from information recorded in the pregnant women's medical files, which are an important instrument for reference and counter-reference between different hospital departments and systematically illustrate all the fundamental data relating to prenatal controls. ${ }^{(6)}$ However, this information may be compromised because of quality problems regarding the way in which this document is filled in by the professionals who conduct the prenatal consultations, as already reported in other studies. ${ }^{(21,22)}$

Another point that suggests that there may a limitation in the present study is in relation to selfreported information. Most information of this nature cannot be validated. For example, the habit of smoking is a variable that is considered to be a classic determinant of LBW. However, in the present study, there were no significant differences between the cases and controls. This finding could lead to the interpretation that the veracity of this self-declared information is doubtful. Nonetheless, this is not a difficulty present in the majority of epidemiological studies. 
On the other hand, it is worth highlighting that a commitment to methodological care was made in the present study, in order to minimize its weak points. One example of this was the implementation of periodontal examinations covering the mouth completely, given that periodontal disease, which remains little studied with regard to its contributions towards systemic illnesses, could be an important confounding factor for LBW. ${ }^{(14)}$

In addition, it is emphasized that while the present study was still at the planning stage, it was adapted to conform with the STROBE recommendations, ${ }^{(23)}$ which provide guidance for publishing papers within the field of epidemiology. The advice contained has the aim of guiding the publication of data coming from observational epidemiological architecture.

Another indicator of the quality of the present study may be represented by the homogeneity of the sample with regard to most of the variables. This respects the principle of maximum resemblance between the case and control groups, which is indispensable for this type of study. To this end, care was taken in simultaneously selecting the sample (one case for every four controls), in an attempt to avoid eligibility bias, particularly in view of the possibility of distortions caused by hospital controls, resulting from the well-known Berkson bias. ${ }^{(24)}$ All the participants were individuals who were attending the hospital unit and had similar characteristics of medical conditions and lifestyles.

Thevariables that presented statisticallysignificant differences between the groups were included in the modeling as confounding factors (urinary infection, number of prenatal consultations and use of medications) even if they were not identified empirically as confounders for the association between maternal arterial hypertension and LBW. Nonetheless, like in any epidemiological study, it is not possible to rule out residual confounding effects from variables that might have an influence on low weight and, at the same time, might be associated with maternal hypertension, but which were not measured in the present investigation.

Despite these limitations, the greatest contribution from this investigation comes from the fact that it presents data from a region with a population from a low social stratum, from the Sertão or backcountry region of northeastern Brazil. Historically, there have been difficulties in mapping out the health problems of this region and publishing the data in scientific media, particularly with regard to systematization of the scientific method. In other words, the contribution that this study makes is that through analytical epidemiological strategies, it presents the high magnitude of the association between maternal arterial hypertension and LBW among a socially disadvantaged population in a developing country.

Lastly, it is recommended that prospective studies, which have the capability to exert greater control over bias, should be conducted in order to elucidate not only the existence of a relationship between these two events, but also the strength of this association. Such studies might enable greater consistency of guidance for health actions among poor populations.

\section{ACKNOWLEDGEMENTS}

To the Science and Technology Support Foundation of the State of Pernambuco for financial support. The authors declare that they do not have any conflicts of interest.

Funding sources: Fundação de Amparo à Ciência e Tecnologia do Estado de Pernambuco (FACEPE), and Universidade Federal do Vale do São Francisco (UNIVASF) - Petrolina, Pernambuco, Brazil.

\section{REFERENCES}

1. Minamisava R, Barbosa MA, Malagoni L, Andraus LMS. Fatores Associados ao Baixo Peso ao Nascer no Estado de Goiás. Rev Eletrônica Enferm. 2006;6(3): 336-349.

2. Passebon E, Bloch KV, Kale PL, Coeli CM. Associação entre peso ao nascer e mortalidade infantil no município de Campos dos Goytacazes - RJ. Cad Saude coletiva. 2006; 14(2):283-296.

3. Organização Mundial da Saúde. CID-

10. Classificação estatística internacional de doenças e problemas relacionados à saúde. $10^{a}$ ed. São Paulo: EDUSP; 1998. 
4. Nascimento LFC. Estudo transversal sobre fatores associados ao baixo peso ao nascer a partir de informações obtidas na sala de vacinação. Rev Bras Saúde Matern Infant. 2003; 3:37-42.

5. Unicef. United Nations Children's Fund. Situação Mundial da Infância 2008. New York: UNICEF; 2008.

6. Ministério da Saúde (BR). Secretaria de Gestão Estratégica e Participativa. DATASUS. Nascidos Vivos - Brasil. Informação de Saúde. Brasília; 2014.

7. Minagawa ÁT, Biagoline REM, Fujimori E, Oliveira IMVD, Moreira APDCA, Ortega LDS. Baixo peso ao nascer e condições maternas no pré-natal. Rev Esc Enferm USP. 2006;4O(4):548-554.

8. Araújo DMR, Pereira NDL, Kac G. Ansiedade na gestação, prematuridade e baixo peso ao nascer: uma revisão sistemática da literatura. Cad Saúde Pública. 2007;23(4):747-756.

9. Ministério da Saúde (BR). Secretaria de Atenção à Saúde. Departamento de Ações Programáticas Estratégicas. Área Técnica de Saúde da Mulher. Pré-natal e puerpério: atenção qualificada e humanizada - manual técnico. Brasilia; 2006.

1O. Carvalho MAB, Melo VH, Zimmermmann JB. Resultados perinatais de gestantes com síndrome hipertensiva da Santa Casa de Misericórdia de Barbacena, Minas Gerais: estudo controlado. Rev Méd Minas Gerais. 2008;18:260-266.

11. Vega CEP, Kahhale S, Zugaib M. Maternal mortality due to arterial hypertension in São Paulo City (1995-1999). Clinics. 2007;62:679-84.

12. VMN, Souza KVD, Freygang TC, Correa V, Saito MR. Mortalidade materna por pré-eclâmpsia/ eclâmpsia em um estado do Sul do Brasil. Rev Bras Ginecol Obstet. 2009; 31: 566-73.

13. Ministério da Saúde (BR). Secretaria de Atenção à Saúde. Departamento de Atenção Básica. Hipertensão arterial sistêmica para o Sistema Único de Saúde. Brasilia; 2006.

14. Gomes-Filho IS, Cruz SS, Rezende EJ, Dos Santos CA, Soledade KR, Magalhães MA, et al. Exposure measurement in the association between periodontal disease and prematurity/low birth weight. J Clin Periodontol. 2007;34(11):957-963.
15. Rothman KJ, Greeland S, Lash TL. Modern Epidemiology. 13 ed. Philadelphia: Lippincott Williams \& Wilkins; 2008.

16. Xiong X, Demianczuk NN, Saunders LD, Wang FL, Fraser WD. Impact of preeclampsia and gestational hypertension on birth weight by gestational age. Am J Epidemiol. 20O2. 155:203209.

17. Odell CD, Kotelchuck M, Chetty VK, Fowler J, Stubblefield PG, Orejuela M, et al. Maternal hypertension as a risk factor for low birth weight infants: comparison of Haitian and AfricanAmerican women. Matern Child Health J. 2006;10:39-46.

18. Salge AKM, Vieira AVC, Aguiar AKA, Lobo SF, Xavier RM, Zatta LT, et al. Fatores maternos e neonatais associados à prematuridade. Rev Eletrônica Enferm. 2009:11(3):642-646.

19. Kilsztajn S, Rossbach A, Carmo MSND, Sugahara GTL. Assistência pré-natal, baixo peso e prematuridade no Estado de São Paulo, 2000. Rev Saúde Pública. 2003;37:303-310.

2O. Cruz SSD, Costa MDCN, Gomes Filho IS, Vianna MIP, Santos CT. Doença periodontal materna como fator associado ao baixo peso ao nascer. Rev Saúde Pública.2005;39:782-7.

21. Oba MDDDV, Tavares MSG. Aspectos positivos e negativos da assistênca pré-natal no município de Ribeirão Preto-SP. Rev Lat Am Enfermagem. 2000;8(2):11-17.

22. Costa GDD, Cotta RMM, Reis JR, SiqueiraBatista R, Gomes Ap, Franceschini SDCC. Avaliação do cuidado à saúde da gestante no contexto do Programa Saúde da Família. Ciênc. Saúde Coletiva 2009;14:1347-1357.

23. Von ELM E, Altman DG, Egger M, Pocock SJ, Gøtzsche PC, Vandenbroucke JP, et al. Strengthening the Reporting of Observational Studies in Epidemiology (STROBE) statement: guidelines for reporting observational studies. BMJ. 2007;335:806-808.

24. Almeida Filho N, Rouquayrol MZ. Introduction to epidemiology. 4th ed. Rio de Janeiro: Guanabara Koogan; 2006. 